\title{
THE COORDINATION OF ACTIVITIES OF THE LAW ENFORCEMENT AGENCIES IN THE FIGHT AGAINST CRIME
}

\author{
Ekaterina S. Azarova \\ Volgograd State University, Volgograd, Russian Federation \\ Vyacheslav I. Vnukov \\ Volgograd State University, Volgograd, Russian Federation
}

\begin{abstract}
Introduction: in modern Russian society, the fight against crime requires the legislative regulation. Crime is a multifaceted phenomenon that is becoming more complex in parallel with the development of society. Its growth makes it necessary to research the fundamentals of the theory and practice of coordinating the activities of the law enforcement agencies in the fight against crime. The important factors from the point of view of the state of coordination activities are their proper organizational support, the development of the right strategies and tactics when performing the necessary actions, as well as their effective use by the law enforcement agencies to curb criminal activity. The authors of the paper set the goal of the study, which is to analyze the coordination activities of the law enforcement agencies in the fight against crime. Methods: the methodological framework for the research is the dialectical-materialistic method of cognition, which includes the elements of system analysis, and the specific scientific methods, such as the logical and legal one. Results: based on the legal analysis, the content of coordination activities as the effective coordinated actions in the fight against crime is revealed. Conclusions: it is revealed that there is a need to adopt a special law aimed at improving the status of prosecutors in the framework of these coordination activities.
\end{abstract}

Key words: coordination, interaction, fight against crime, coordination activities, prosecutor's office.

Citation. Azarova E.S., Vnukov V.I. The Coordination of Activities of the Law Enforcement Agencies in the Fight Against Crime. Legal Concept $=$ Pravovaya paradigma, 2021, vol. 20, no. 2, pp. 26-32. (in Russian). DOI: https://doi.org/10.15688/lc.jvolsu.2021.2.4

\section{КООРДИНАЦИЯ ДЕЯТЕЛЬНОСТИ ПРАВООХРАНИТЕЛЬНЫХ ОРГАНОВ ПО БОРЬБЕ С ПРЕСТУПНОСТЬЮ}

\author{
Екатерина Сергеевна Азарова \\ Волгоградский государственный университет, г. Волгоград, Российская Федерация \\ Вячеслав Иванович Внуков \\ Волгоградский государственный университет, г. Волгоград, Российская Федерация
}

\footnotetext{
Введение: в современном российском обществе борьба с преступностью требует законодательного урегулирования. Преступность представляет собой многогранное явление, которое усложняется параллельно развитию социума. Ее рост обусловливает необходимость научного исследования основ теории и практигі ки координации деятельности правоохранительных органов по борьбе с преступностью. Важными фактора夗 ми с точки зрения состояния координационной деятельности являются ее надлежащее организационное ‡. обеспечение, выработка правильных стратегий и тактик при выполнении необходимых действий, а также эффективность их применения правоохранительными органами для пресечения преступной деятельности.
} (a) 
Авторами в данной статье поставлена цель исследования, которая состоит в анализе координации деятельности правоохранительных органов по борьбе с преступностью. Методы: методологическую основу исследования составляют диалектико-материалистический метод познания, включающий в себя элементы системного анализа, и частные научные методы, такие как логико-юридический, историко-сравнительный. Результаты: на основании правового анализа раскрывается содержание координационной деятельности как эффективных согласованных действий в борьбе с преступностью. Выводы: выявлена необходимость в принятии специального закона, направленного на повышение статуса прокуроров в рамках этой координационной деятельности.

Ключевые слова: координация, взаимодействие, борьба с преступностью, координационная деятельность, прокуратура.

Цитирование. Азарова Е. С., Внуков В. И. Координация деятельности правоохранительных органов по борьбе с преступностью // Legal Concept = Правовая парадигма. - 2021. - T. 20, № 2. - C. 26-32. - DOI: https://doi.org/10.15688/lc.jvolsu.2021.2.4

\section{Введение}

Правовой основой взаимодействия правоохранительных органов в сфере борьбы с преступностью выступает Конституция Российской Федерации, а также федеральные законы и подзаконные нормативные акты. Так, «Положение о координации деятельности правоохранительных органов по борьбе с преступностью», утвержденное Указом Президента Российской Федерации № 567 от 18.04.1996 г., определяет механизм организации взаимодействия правоохранительных органов по разработке мероприятий, направленных на борьбу с преступностью. Также сформулированы направления координационной деятельности прокуратуры, определены полномочия участников координационной деятельности. В Положении о координации оп- ределены субъекты координационной деятельности (рис. 1).

Необходимо отметить, что Положение о координации не ограничивает взаимодействие органов прокуратуры в процессе их координации. Согласно п. 7 Положения о координации к координационной деятельности могут быть привлечены другие должностные лица правоохранительных органов, руководители органов государственной власти субъектов Российской Федерации, органов местного самоуправления.

Прокуратура является государственным органом, способным быть координатором деятельности правоохранительных органов по борьбе с преступностью. Ю.В. Капитонова отметила, что «в силу своего правового статуса именно прокуратура в состоянии выступать координатором, нисколько не подавляя самостоятельности остальных участников

\section{органы прокуратуры}

\section{органы внутренних дел РФ}

органы федеральной службы безопасности

органы уголовно-исполнительной системы

таможенные органы РФ

следственные органы

Рис. 1. Субъекты координационной деятельности 
названной деятельности, не ущемляя их прав, оставаясь при этом органом надзора за соблюдением законности в деятельности всех правоохранительных органов» [6, с. 16-17]. Так, например, А.Я. Меженцева является сторонником идеи сохранения лидирующей роли прокуратуры в координации борьбы с преступностью и закрепления ее на прочной правовой основе [10, с. 30]. Л.М. Давыденко также считает, что прокуратура играет важную роль в организации и координации борьбы с преступностью [3, с. 80].

\section{Понятие «координация» и «взаимодействие»}

В юридической литературе часто используются понятия «координация» и «взаимодействие». Например, А.А. Максуров утверждает, что координационная деятельность представляет собой такой тип деятельности, направленной на установление оптимального баланса между различными видами властной деятельности компетентного органа с целью повышения эффективности и качества. Он указывает, что ее следует понимать как деятельность, направленную на удовлетворение потребностей и интересов общества в целом, группы и индивида [9, с. 11].

А.В. Кудашкин также категорию «координация» связывает с категорией «взаимодействия». В юридической литературе под координацией обычно понимается взаимосогласованная деятельность различных органов для достижения общей цели. Координация деятельности правоохранительных органов в борьбе с преступностью представляет одну из главных функций прокуратуры, которая осуществляется наряду с другими функциями по обеспечению, объединению и укреплению верховенства закона [8].

Понятие «взаимодействие» достаточно широко употребляется в научной литературе и используется в практике. М.Ф. Кобзарев отмечает, что данное понятие многогранно, его следует рассматривать с позиции различных наук. Например, с точки зрения философской науки, как категорию, используемую для эффективной деятельности субъекта в отношении с другими субъектами, не подчиненными ему [7, с. 4].
Отметим, что понятие «взаимодействие» следует рассматривать как фундаментальную философскую категорию. С точки зрения философского анализа бытие представлено в различных формах. Образно говоря, как бытие природы, бытие человека, бытие идеального и т. д. Соответственно бытие включает в себя не только формы, но и элементы, которые между собой взаимодействуют. Каждая вещь в реальности находится в отношении с другими окружающими ее вещами. Как отметил К. Маркс, свойства вещей проявляются в процессе отношения ее с другими вещами.

Проблема обнаружения свойств объекта через взаимодействие возникла в Древней Греции. Гераклит считал, что природа вещей и явлений, их свойства раскрываются во взаимодействии вещей и явлений. В XVII в. английский философ Ф. Бэкон рассуждал о том, что предметы, исключенные из обусловленности природы, не могут существовать. Немецкий философ Г.В.Ф. Гегель в XIX в. указал, что понятие всеобщего диалектического взаимодействия намного глубже представлений о линейных взаимодействиях. Иными словами, для познания какого-либо объекта необходимо выявить его признаки, исследовать их в динамике, то есть во взаимодействии с другими объектами. Можно утверждать, что мысль, характерная для XIX в., актуальна в современном мире.

Современная философская мысль взаимодействие рассматривает как категорию, в которой отражены процессы воздействия одних объектов на другие. Как правило, взаимодействие носит универсальный характер. Сложное взаимодействие составляет сущность материального мира.

Анализируя правовой аспект взаимодействия прокураторы с правоохранительными органами, следует выделить два направления. Во-первых, надзор прокуратуры за исполнением законов в деятельности органов следствия и судов. Данная деятельность осуществляется прокуратурой с 1922 г., задачи которой отражены в Положении о прокурорском надзоре 1922 и 1955 годов. Во-вторых, координация их деятельности по борьбе с преступностью. Так, в Положении о прокурорском надзоре 1922 г. говорится, что прокуратура создается в интересах борьбы с преступностью. 
Освещение вопросов координации работы было изучено в малом количестве. Так, отдельные вопросы координационной деятельности отражены в документах Генеральной прокуратуры СССР. Например, в п. 4 приказа Генерального прокурора СССР № 53 «О мерах по дальнейшему совершенствованию деятельности органов прокуратуры в борьбе с преступностью и нарушениями законности» речь идет об обязанности прокурора устранять разобщенность в деятельности правоохранительных органов по борьбе с преступностью. Также прокурор должен систематически обсуждать состояние преступности и определять меры по координации следственных действий.

Координация деятельности правоохранительных органов значительно укрепила свои силы в конце 70-х гг. XX века. Несмотря на это Закон о прокуратуре СССР имел недостатки. Например, в ст. 3 не раскрыто содержание и цели координационной деятельности. Прокурор был обязан координировать деятельность правоохранительных органов не только по борьбе с преступлениями, но и правонарушениями. На практике были выделены следующие формы координации прокурором деятельности правоохранительных органов: заседание координационных советов, совместное изучение преступлений и оказание помощи населению в борьбе с правонарушениями.

Анализируя проблемные моменты координации деятельности по борьбе с преступностью, отметим отсутствие единого мнения у ученых в вопросе организации данной деятельности. Это связано с тем, что обязанности по координации деятельности были возложены, с одной стороны, на прокуратуру, с другой стороны, на органы государственной власти и созданные последними координационные структуры. В 60-е гг. XX в. П.Т. Васьковым было предложено образование специального органа, занимающегося координацией деятельности по обеспечению законности в каждом городе советского общества. В состав такого органа необходимо включать руководителей суда, прокуратуры, милиции. Образование его позволило бы, по мнению автора, усилить целенаправленность в действиях государственной власти. Данная идея получила критическую оценку, так как созда- ние такого органа противоречило закону в разделе независимости прокуратуры на местах.

\section{Координационная деятельность}

Отметим, что важными факторами с точки зрения состояния координационной деятельности являются ее надлежащее организационное обеспечение, выработка правильных стратегий и тактик при выполнении необходимых действий, а также эффективность их применения правоохранительными органами для пресечения преступной деятельности [1]. Активная и последовательная позиция правоохранительных органов в борьбе с преступностью может обеспечить скоординированную и эффективную работу, направленную на предупреждение преступности, выявление и пресечение конкретных видов преступного поведения, а также выявление и устранение факторов, составляющих преступность.

Прокуратура занимает особое положение в системе органов государственной власти и наделена полномочиями координирующего органа в связи с тем, что она обладает необходимой информацией в области борьбы с преступностью. Если быть точными, то это сведения о выявленных преступлениях, их раскрытии, расследовании и причинах, лежащих в основе их совершения, а также результаты поддержания государственного обвинения прокурором. Координационной деятельности Прокуратуры Российской Федерации характерны различные правовые, организационные и другие вопросы (см. рис. 2).

Отметим, что, учитывая криминогенную ситуацию, координация деятельности правоохранительных органов может быть проведена по поручению руководителей федеральных правоохранительных органов.

Важной частью координационной деятельности правоохранительных органов является объединение целей по борьбе с преступностью, а также реализация и выработка мер по оперативному выявлению и пресечению преступлений и устранению факторов, вызывающих преступления. В этом плане прокуратура занимает особое положение в системе органов государственной власти, как следствие, обладает полномочиями координирующего органа. В сфере борьбы с преступнос- 


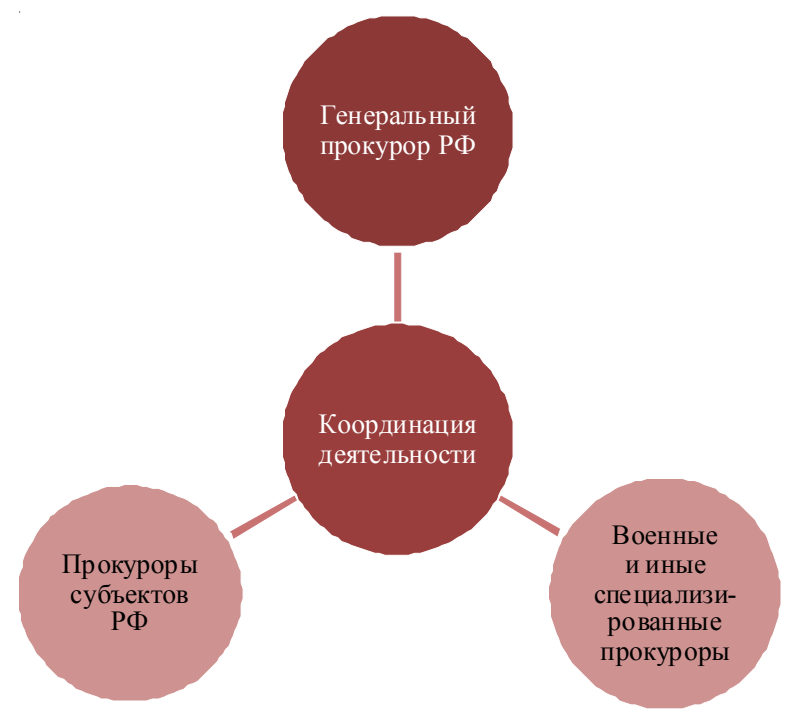

Рис. 2. Координация деятельности правоохранительных органов по борьбе с преступностью

тью прокуратура в большей степени владеет информацией о выявленных преступлениях.

Обратим внимание, что не каждое взаимодействие правоохранительных органов находится в основе координационной деятельности, а только такое, какое возникает в пределах координационных отношений [4, с. 14]. В этом аспекте С.Б. Жунусов выделяет прокурорскую практику как наиболее эффективную форму взаимодействия правоохранительных органов в сфере координационной деятельности. Прокуроры имеют возможность получить информацию о текущей ситуации, структуре и динамике преступления, а также о вопросах, связанных с раскрытием и расследованием, а затем могут успешно использовать полученную информацию для решения проблемных вопросов [7, с. 56].

По мнению В.Г. Бессарабова [2, с. 188], необходимо усилить правовое обеспечение в сфере координационной деятельности, чтобы повысить эффективность работы прокуратуры, выполняющей координационные функции в борьбе с преступностью. Помимо этого следует совершенствовать формы и методы взаимодействия прокуратуры и других правоохранительных органов с судами, государственными органами власти. Это требует нормативная регламентация вопросов, связанных с процедурами разрешения конфликтов, возникающих в процессе подготовки и обмена информацией, разработки и реализации совместной деятельности, принятия решений и коор- динации деятельности. Что касается правоохранительной деятельности в сфере борьбы с преступностью, мнение о том, что координация как «управленческая категория» предполагает обязательное наличие полномочий координатора по отношению к не подчиненным друг другу структурам, в некоторой степени необоснованно. Главное в реализации координации - взаимодействие структур для решения общей задачи, предотвращения, выявления и расследования преступлений.

\section{Выводы}

Говоря о возможных способах повышения эффективности согласованных действий в борьбе с преступностью и повышения статуса прокуроров в рамках этой деятельности, можно считать целесообразным предложить корректировку закона для совершенствования нормативно-правовой базы [5]. Необходимо принятие специального закона, который определил бы координационную деятельность с точки зрения значимости этого феномена для современного правового общества. Закон должен более точно определять компетенции сотрудников, вовлеченных в координационную деятельность на различных уровнях, и определять четкие границы между этими полномочиями каждого ведомства, чтобы избежать дублирования и необоснованного использования сил и возможностей. Мы считаем, что прокуратуре необходимо предоставить более 
широкие полномочия, например, возможность привлечения к ответственности руководителей органов государственной власти в случае неисполнения принятых решений.

\section{СПИСОК ЛИТЕРАТУРЫ}

1. Азарова, Е. С. Фактор усмотрения суда при доказывании в уголовном процессе / Е. С. Азарова // Доказательства и доказывание в уголовном судопроизводстве: история, современность и перспективы развития : сб. ст. по материалам Междунар. науч.-практ. конф., посвящ. 95-летию со дня рождения Цили Моисеевны Каз (г. Саратов, 3 апр. 2020 г.) / редкол.: Ю. В. Францифоров [и др.]. - Саратов : Изд-во Сарат. гос. юрид. акад., 2020. - С. 5-7.

2. Бессарабов, В. Г. Правозащитная деятельность российской прокуратуры (1722-2002 гг.): история, события, люди / В. Г. Бессарабов. - М. : [б. и.], 2003. $-414 \mathrm{c}$.

3. Давыденко, Л. М. Организация деятельности районной, городской прокуратуры по профилактике преступлений / Л. М. Давыденко. - Харьков : Фолио, 1990. - $218 \mathrm{c}$.

4. Жунусов, С. Б. Процессуальное положение прокурора на досудебных стадиях уголовного процесса : автореф. дис. ... канд. юрид. наук / Жунусов Серик Базылханович. - Караганда : КЮИ МВД РК им. Б. Бейсенова, 2009. - 29 с.

5. Исаева, А. М. Координация деятельности правоохранительных органов по борьбе с преступностью. Проблемы и пути повышения статуса Прокуратуры Российской Федерации в этой деятельности / А. М. Исаева // Закон и право. - 2020. № 8. - С. 34-36.

6. Капитонова, Ю. В. Основы координации прокуратурой деятельности правоохранительных органов по борьбе с преступностью : автореф. дис. ... канд. юрид. наук / Капитонова Юлия Владимировна. - М., 2002. -27 c.

7. Кобзарев, Ф. М. Прокуратура и суд в уголовном процессе: условия и формы взаимодействия / Ф. М. Кобзарев. - М. : Изд-во Моск. психолого-социального ин-та, 2005. - 104 с.

8. Координация прокуратурой деятельности правоохранительных органов по борьбе с преступностью : монография / под общ. ред. Ф. М. Кобзарева. - М. : Проспект, 2016. - 254 с.

9. Максуров, А. А. Координационная деятельность в правовой системе общества : дис. ... канд. юрид. наук / Максуров Алексей Анатольевич. Ярославль : Изд-во Ярослав. гос. ун-та, 2001. - 193 с.

10. Меженцева, А. Я. О концепции прокурорского надзора / А. Я. Меженцева // Научная информация по вопросам борьбы с преступностью. - М. :
Изд-во НИИ проблем укрепления законности и правопорядка, 1989. - Вып. 118. - С. 27-34.

\section{REFERENCES}

1. Azarova E.S. Faktor usmotreniya suda pri dokazyvanii v ugolovnom protsesse [Factor of Discretion of the Court in Proving in Criminal Proceedings]. Frantsiforov Yu.V. et al., eds. Dokazatelstva $i$ dokazyvaniye $v$ ugolovnom sudoproizvodstve: istoriya, sovremennost $i$ perspektivy razvitiya: sb. st. po materialam Mezhdunar. nauch.-prakt. konf., posvyashch. 95-letiyu so dnya rozhdeniya Tsili Moiseyevny Kaz (g. Saratov, 3 apr. 2020 g.) [Evidence and Proof in Criminal Proceedings: History, Modernity and Development Prospects. Collection of Articles Based on the Materials of the International Scientific and Practical Conference Dedicated to the $95^{\text {th }}$ Anniversary of the Birth of Tsili Moiseevna Kaz]. Saratov, 2020, pp. 5-7.

2. Bessarabov V.G. Pravozashchitnaya deyatel'nost' rossijskoj prokuratury (17222002 gg.): istoriya, sobytiya, lyudi [Human Rights Activities of the Russian Prosecutor's Office]. Moscow, 2003. 414 p.

3. Davydenko L.M. Organizaciya deyatel'nosti rajonnoj, gorodskoj prokuratury po profilaktike prestuplenij [Organization of the Activities of the District, City Prosecutor's Office for the Prevention of Crimes]. Kharkov, Folio Publ., 1990. 218 p.

4. Zhunusov S.B. Processual'noe polozhenie prokurora na dosudebnyh stadiyah ugolovnogo processa: avtoref. dis. ... kand. yurid. nauk [Procedural Position of the Prosecutor at the Pre-Trial Stages of the Criminal Process. Cand. jurid. sci. abs. diss.]. Karaganda, KYuI MVD RK im. B. Beysenova, 2009. 29 p.

5. Isayeva A.M. Koordinatsiya deyatelnosti pravookhranitelnykh organov po borbe s prestupnostyu. Problemy i puti povysheniya statusa Prokuratury Rossiyskoy Federatsii V etoy deyatelnosti [Coordination of the Activities of Law Enforcement Agencies in the Fight Against Crime. Problems and Ways to Improve the Status of the Prosecutor's Office of the Russian Federation in this Activity]. Zakon $i$ pravo [Law and Law], 2020, no. 8, pp. 34-36.

6. Kapitonova Yu.V. Osnovy koordinacii prokuraturoj deyatel'nosti pravoohranitel'nyh organov po bor'be s prestupnost'yu: avtoref. dis. ... kand. yurid. nauk [Fundamentals of Coordination by the Prosecutor's Office of the Activities of Law Enforcement Agencies in the Fight Against Crime. Cand. jurid. sci. abs. diss.]. Moscow, 2002. 27 p.

7. Kobzarev F.M. Prokuratura i sud v ugolovnom processe: usloviya $i$ formy vzaimodejstviya 


\section{ГЛАВНАЯ ТЕМА НОМЕРА}

[Prosecutor's Office and Court in Criminal Procedure: Conditions and Forms of Interaction]. Moscow, Izd-vo Mosk. psikhologo-sotsialnogo in-ta, 2005. 104 p.

8. Kobzarev F.M., ed. Koordinatsiya prokuraturoy deyatelnosti pravookhranitelnykh organov po borbe s prestupnostyu: monografiya [Coordination by the Prosecutor's Office of the Activities of Law Enforcement Agencies in the Fight Against Crime]. Moscow, Prospekt Publ., 2016. 254 p.
9. Maksurov A.A. Koordinatsionnaya deyatelnost $v$ pravovoy sisteme obshchestva: dis. ... kand. yurid. nauk [Coordination Activity in the Legal System of Society. Cand. jurid. sci. diss.]. Yaroslavl, Izd-vo Yaroslav. gos. un-ta, 2001. 193 p.

10. Mezhentseva A.Ya. O kontseptsii prokurorskogo nadzora [On the Concept of Prosecutor's Supervision]. Nauchnaya informatsiya po voprosam borby s prestupnostyu [Scientific Information on the Fight Against Crime], 1989, iss. 118, pp. 27-34.

\section{Information About the Authors}

Ekaterina S. Azarova, Candidate of Sciences (Jurisprudence), Associate Professor, Department of Criminal Procedure and Criminalistics, Volgograd State University, Prosp. Universitetsky, 100, 400062 Volgograd, Russian Federation, aes2404@yandex.ru, https://orcid.org/0000-0001-5130-1653

Vyacheslav I. Vnukov, Candidate of Sciences (Jurisprudence), Associate Professor, Department of Criminal Procedure and Criminalistics, Volgograd State University, Prosp. Universitetsky, 100, 400062 Volgograd, Russian Federation, vnukov78@yandex.ru, https://orcid.org/0000-0002-2942-1920

\section{Информация об авторах}

Екатерина Сергеевна Азарова, кандидат юридических наук, доцент кафедры уголовного процесса и криминалистики, Волгоградский государственный университет, просп. Университетский, 100, 400062 г. Волгоград, Российская Федерация, aes2404@yandex.ru, https://orcid.org/0000-0001-5130-1653

Вячеслав Иванович Внуков, кандидат юридических наук, доцент кафедры уголовного процесса и криминалистики, Волгоградский государственный университет, просп. Университетский, 100, 400062 г. Волгоград, Российская Федерация, vnukov78@yandex.ru, https://orcid.org/0000-0002-2942-1920 